\title{
Pythagorean Fuzzy Analytical Network Process (ANP) and Its Application to Warehouse Location Selection Problem
}

\author{
Tutku Tuncalı Yaman \\ Beykent University Management Information \\ Systems Department Istanbul, Turkey \\ Email: tutkuyaman@beykent.edu.tr
}

\begin{abstract}
Although new techniques are added to multicriteria decision-making (MCDM) techniques every day, fuzzy applications of current and proven methods also take a large place in the literature. The main subject of this study is to propose an extension of Pythagorean fuzzy sets (PFS), which are useful to overcome the uncertainty in multi-criteria decision processes, to the well-known Analytical Network Process (ANP) technique. For this purpose, an empirical application of the proposed method was carried out in defining criteria weights of the warehouse location selection problem in the medical sector.
\end{abstract}

\section{INTRODUCTION}

A NALYTICAL approaches to decision-making processes have introduced to the academic world by the pioneers of the field and then applied to real business problems since the 80s. [1-4] made significant contributions to the field of fuzzy logic in order to reflect the human factor in methodical decision-making processes.

After the 2000s, the fuzzy logic concept has been diversified with developments such as type-2 fuzzy sets, Intuitionistic Fuzzy Sets (IFS), Pythagorean Fuzzy Sets (PFS), Neutrosophic Sets (NS) and Hesitant Fuzzy Sets (HFS). Thus, the uncertainty, which is caused by the human factor, has been tried to be covered as much as possible. Many MCDM methods have been proposed with different fuzzy approaches [5]. [6] introduced ANP as a MCDM technique for decision problems, which have interdependence between criteria and alternatives. The method is applied as a successor to DEMATEL [7], which is used especially in exploratory studies, in determining the causal relationships between the criteria and creating a network structure of them. Then the relative importance levels of the criteria can be obtained by sorting the determined weight values. It is possible to use these weight values as inputs for different MCDM methods. ANP and AHP have a common theoretical application steps with different perspective and outputs. Albeit, AHP recognizes independency among criteria, in ANP, correlations among criteria have an important role. AHP is not sufficient to address the complexity of real world problems on its hierarchical structure; ANP presents a problem in a network of criteria and alternatives, which are strongly intercorrelated [8].

The adaptations of the ANP method for the different fuzzy approaches such as type- 2 and IFS have already been realized. In this study, it is expected to fill the gap in the literature by proposing the application of a Pythagorean Fuzzy ANP method (PFANP). Thus, the Pythagorean fuzzy Analytic Hierarchy Process (PFAHP), which was detailed in [9], was adapted to ANP. The application of the proposed technique was carried out in the context of the location selection problem (WLSP), which was previously handled by a few researchers. In this paper, an empirical application of WLSP is made specifically for the medicine/pharmaceutical industry. Although it is a crucial factor in supply chain management processes [10], the choice of warehouse location in this sector has not been handled as an MCDM problem before.

The content of the article is organized as follows; in the following section, the state-of-art WLSP and aim of the study are detailed. In Section III, a literature review is carried out by referring academic articles about the WLSP. Section IV includes the methodological perspective of the proposed technique in detail. Section V consists of the empirical results of the study. Conclusion and details of planned future research are given in the last section.

\section{OBJECTIVE OF THE STUDY}

The main motivation of this study is proposing a Pythagorean fuzzy extension of the ANP method. As the application area of the method, the WLSP, which plays a critical role in the effective realization of all logistics activities, was chosen. The criteria that are important for the selection of the storage location, with availability and cost priority, are given for the medical sector considered within the scope of the research: C1: Proximity to target markets (hospitals, pharmacies), C2: Proximity to the ports and customs, C3: Proximity to the pharmaceutical production centers, C4: The location decision of a warehouse must be submitted together with capacity and demand estimation, C5: The proximity of qualified workforce, C6: The infrastructure of the area (electricity, water, sewage, transportation, natural gas, etc.), C7: The climate of the location, C8: Ground properties of the location (impact of construction on excavation cost), C9: Leasing cost of the location, C10: Traffic density of location.

The proposed method will be detailed in the methodology section and the literature review carried out within the scope of the subject will be included in the next section. 


\section{LITERATURE REVIEW}

With the review purposes, a search was made in the Scopus database on $1^{\text {st }}$ of August, 2020, with "Article Title, Abstract, and Keywords" gives the following frequencies: 9600 for Analytic Network Process (ANP), 503 for Pythagorean fuzzy sets, 318 for fuzzy ANP, and 0 Pythagorean fuzzy ANP. Similarly, when the WLSP is examined, a total of 21 studies have been found in the same database since 2011. The most recent study carried out in the context of this problem was performed in the field of humanitarian relief logistics with the multi-objective fuzzy mathematical programming method [11]. In another study, same problem was solved with the spherical fuzzy CODAS method [12]. In [13], authors attempted to solve WLSP about the storage of agricultural products by MCDM methods such as SAW, AHP and TOPSIS. For further studies on the subject, please refer to [14-32].

\section{Methodology}

In cases where there are complex causality relationships between the criteria at the beginning of the MCDM problems, the network structure between the criteria is determined in order to identify and address them in the model, and then the importance levels of the criteria are determined by considering the degree of influence on each other [33]. In this study, by following the same process, the network structure for 10 criteria recommended by experts for the storage location selection problem was determined by the Pythagorean fuzzy DEMATEL (PFDEMATEL) method and then the weight values of the criteria were determined through the proposed Pythagorean fuzzy ANP (PFANP) method. Preliminaries of PFS, and detailed calculation steps of PFDEMATEL, which were used in calculation steps of this study, can be found in $[34,35]$ respectively. The use of the ANP method with the PFSs and its extensions has not proposed in the literature, and also the application of PFS based ANP has never been used in a medical sector WLSP before. Calculation steps of PFANP framework are described below.

\section{A. Pairwise Comparisons}

Based on the network structure created for the criteria with the PFDEMATEL method [35], the criteria affecting each criterion are subjected to pairwise comparisons in the context of the related criterion. These comparisons are made by experts of the subject on the basis of the linguistic variables [9] given in Table I below. Here, membership and non-membership degrees of PFNs are denoted as $\mu$ and $v$, respectively. Given linguistic expressions are converted to $\mathrm{PF}$ values to obtain PF pairwise matrices for each criterion and for each expert.

\section{B. Aggregated Pairwise Comparison Matrix}

The PF weighted power geometric (PFWPG) operator [36] is used to obtain the Aggregated Pairwise Comparison Matrix $\left(R=\left(r_{i k}\right)_{m \times m}\right)$, by averaging the evaluations made by experts. It is possible to assign different weight values to different experts evaluating here. However, the sum of these weights should be equal to 1 . Let $\widetilde{P}_{l}=\left\langle\mu_{i} \mid v_{i}\right\rangle, i=1,2, \ldots, n$ be a collection of PFNs and $W=\left(w_{1}, w_{2}, \ldots, w_{n}\right)^{T}$, is the weight vector of $P_{i}$ with $\sum_{i=1}^{n} w_{i}=1$.

Then the PFWPG operator is, $\operatorname{PFWPG}\left(\widetilde{P}_{1}, \ldots, \widetilde{P_{n}}\right)=$ $\left(\sqrt{\left(1-\prod_{i=1}^{n}\left(1-\mu_{i}^{2}\right)^{w_{i}}\right)}, \sqrt{\left(1-\prod_{i=1}^{n}\left(1-v_{i}^{2}\right)^{w_{i}}\right)}\right)$

\section{Priority Vector}

According to [37], the idea of a priority vector has much less validity for an arbitrary positive reciprocal matrix than for a consistent and a near consistent matrix. Here, [9]'s point of view is followed and the Priority Vector $A=$ $\left(a_{i}\right)_{1 \times m}$ is created on a relative dominance basis. The calculation steps are as follows:

First, differences matrix $D=\left(d_{i k}\right)_{m \times m}$ is constructed using Equations 2 and 3 below.

$$
\begin{aligned}
& d_{i k_{L}}=\mu_{i k_{L}}^{2}-v_{i k_{U}}^{2} \\
& d_{i k_{U}}=\mu_{i k_{U}}^{2}-v_{i k_{L}}^{2}
\end{aligned}
$$

Then, interval multiplicative matrix $S=\left(s_{i k}\right)_{m \times m}$ is found using Equations 4 and 5.

$$
\begin{aligned}
& s_{i k_{L}}=\sqrt{1000^{d_{i k_{L}}}} \\
& s_{i k_{U}}=\sqrt{1000^{d_{i k_{U}}}}
\end{aligned}
$$

Determinacy value $\tau=\left(\tau_{i k}\right)_{m \times m}$ of the Aggregated Pairwise Comparison Matrix is calculated using following Equation 6.

$$
\tau_{i k}=1-\left(\mu_{i k_{U}}^{2}-\mu_{i k_{L}}^{2}\right)-\left(v_{i k_{U}}^{2}-v_{i k_{L}}^{2}\right)
$$

Matrix of Weights $T=\left(t_{i k}\right)_{m \times m}$ is obtained using Equation 7 below.

$$
t_{i k}=\left(\frac{s_{i k_{L}}+s_{i k_{U}}}{2}\right) \tau_{i k}
$$

Normalization of Matrix of Weights gives us the Priority Vector $A$ of each criterion. The normalization operator is,

$$
a_{i}=\frac{\sum_{k=1}^{m} t_{i k}}{\sum_{i=1}^{m} \sum_{k=1}^{m} t_{i k}}
$$

\section{Super Matrix}

After creating a Priority Vector $\left(a_{i}\right)$ for each criterion, as described in previous steps, the Super Matrix ( $W=$ $\left.\left(w_{i}\right)_{m \times m}\right)$ is created by listing local priority vectors in the appropriate columns of $W$.

\section{E. Global Weights}

Once the Super Matrix is created, a stationary Limit Matrix (LM) is obtained by multiplying $W$ with infinite times using Equation 9 below.

$$
\lim _{k \rightarrow \infty}(W)^{k}
$$

The idea behind that, obtaining the cumulative influence of each element on every other interacted element. In practice, it is necessary to raise the super matrix to the power $k=2 n+1$ where $n$ is an arbitrary large number [38]. Each column of the resulting LM will be equal to 1 . Any of the columns of the LM will give us the Priority Vector of the criteria in our problem. By performing previously detailed five steps of PFANP algorithm, an empirical application is done in order to determine criteria weights by concerning 
casual relationships between criteria of WLSP. In the following section, the results of the application are given in detail.

\section{EMPIRICAL RESULTS}

In order to demonstrate the empirical application of the PFANP method, the WLSP, which is one of the important supply chain management problems, is discussed. In order to obtain the network structure on the basis of 10 criteria given in the Section II, PFDEMATEL method [35] was applied after obtaining linguistic evaluations of 5 experts in the field. After revealing cause and effect groups of criteria, the Super Matrix design was obtained [39]. Then criteria based pairwise comparisons were made by 3 experts through linguistic expressions are given in Table I and Pairwise Comparison Matrices were obtained for each criterion on expert basis. Since the matrices contained linguistic expressions, they were converted to PF values, as presented in Table I. Then $R$ was calculated using the PFWPG operator provided in Equation 1 by giving equal weight $(0.3 \overline{3})$ to each expert. Then expert assessments for each criterion were combined. Priority Vectors for each criterion are calculated using Equations 2-8, respectively. These vectors were used to construct the Super Matrix. A stationary Limit Matrix was found using Equation 9. Any column of the Limit Matrix can be used as Global Weights' of criteria. These weights are detailed in Table II below. Since in PFDEMATEL results, the cause group consists of $\mathrm{C} 2, \mathrm{C} 3, \mathrm{C} 4$ and $\mathrm{C} 8$. The most important criterion in cause group is $\mathrm{C} 4$ with the highest $(c+r)$ value. $\mathrm{C} 1, \mathrm{C} 6, \mathrm{C} 7, \mathrm{C} 9$ and $\mathrm{C} 10$ are listed in effect group [39]. According to the global weight figures of PFANP, the first four important criteria in WLSP are found as C7, C10, C5 and C2, respectively.

\section{CONCLUSION}

This paper aimed to demonstrate the Pythagorean fuzzy extension of the well-known ANP method. In line with the mentioned objective and due to complexity of the problem, a combined application of PFDEMATEL and PFANP is performed. The use of DEMATEL's outputs as inputs in ANP is suggested as a solution [17] to the problem of dependence and feedback among each measurement criteria. As an illustrative example, the WLSP was held. It is important for companies to determine the optimal locations of warehouses, which have a critical role in supply chain and logistics management. On the contrary, the WLSP has not been dealt with much in the literature, and its application has also not been encountered especially for the medical sector. In this context, the example was found to be appropriate to be given as a medical sector application by hoping to guide the professionals of the field.

For future directions, the proposed method can be applied in different problems, and its effectiveness can be evaluated by dealing with different types of fuzzy set extensions. A sensitivity analysis, which can evaluate different weight values of different fuzzy extensions of ANP, can help us in finding the superior approach for the handled problem. Group decision-making perspective of [40] can also be pursued in pair-wise comparisons' evaluations of experts. Plus, one step after the proposed method, an MCDM technique in the selection of potential alternatives can be implemented that uses global criteria weights of the PFANP as input. Hence, it is hoped that a comprehensive decisionmaking system can be created.

TABLE I.

RATING SCALES OF LiNGUisTiC TERMS

\begin{tabular}{|l|c|c|c|c|}
\hline \multirow{2}{*}{\multicolumn{1}{|c|}{ Linguistic terms }} & \multicolumn{4}{|c|}{ PFN equivalents IVPF numbers } \\
\cline { 2 - 5 } & $\mu_{L}$ & $\mu_{U}$ & $v_{L}$ & $v_{U}$ \\
\hline Certainly Low Importance & 0 & 0 & 0.9 & 1 \\
\hline Very Low Importance & 0.1 & 0.2 & 0.8 & 0.9 \\
\hline Low Importance & 0.2 & 0.35 & 0.65 & 0.8 \\
\hline Below Average Importance & 0.35 & 0.45 & 0.55 & 0.65 \\
\hline Average Importance & 0.45 & 0.55 & 0.45 & 0.55 \\
\hline Above Average Importance & 0.55 & 0.65 & 0.35 & 0.45 \\
\hline High Importance & 0.65 & 0.8 & 0.2 & 0.35 \\
\hline Very High Importance & 0.8 & 0.9 & 0.1 & 0.2 \\
\hline Certainly High Importance & 0.9 & 1 & 0 & 0 \\
\hline Exactly Equal & 0.1965 & 0.1965 & 0.1965 & 0.1965 \\
\hline
\end{tabular}

TABLE II.

GLOBAL WEIGHTS

\begin{tabular}{|l|c|c|}
\hline \multicolumn{1}{|c|}{ Criteria } & Weight & Rank \\
\hline C1. Proximity to target markets & 0.0444 & 8 \\
\hline C2. Proximity to the ports and customs & 0.1106 & 4 \\
\hline C3. Proximity to the pharmaceutical... & 0.0958 & 5 \\
\hline C4. The location decision of a warehouse must... & 0.0428 & 9 \\
\hline C5. The proximity of qualified workforce & 0.1172 & 3 \\
\hline C6. The infrastructure of the area & 0.0424 & 10 \\
\hline C7. The climate of the location & 0.2038 & 2 \\
\hline C8. Ground properties of the location & 0.0918 & 6 \\
\hline C9. Leasing cost of the location & 0.0452 & 7 \\
\hline C10. Traffic density of location & 0.2056 & 1 \\
\hline
\end{tabular}

\section{REFERENCES}

[1] L. Zadeh, "Fuzzy-set-theoretic interpretation of linguistic hedge", Journal of Cybernetics, vol. 2, 1972, pp. 4-34. https://doi.org/10.1080/01969727208542910

[2] L. Zadeh, "The concept of a linguistic variable and its application to approximate reasoning-1", Information Sciences, 1975, pp. 199-249. https://doi.org/10.1016/0020-0255(75)90036-5

[3] R.R. Yager, "A characterization of the extension principle," Fuzzy Sets and Systems, vol. 18, no. 3, 1986, pp. 205-217. https://doi.org/10.1016/0165-0114(86)90002-3

[4] K. Atanassov, "Intuitionistic fuzzy sets", Fuzzy Sets and Systems, vol. 20, no.1, 1986, pp.87-96. https://doi.org/10.1016/S01650114(86)80034-3

[5] E. Bolturk, "Pythagorean fuzzy CODAS and its application to supplier selection in a manufacturing firm", Journal of Enterprise Information Management, vol.31, no.4, 2018, pp.550-564. https://doi.org/10.1108/JEIM-01-2018-0020

[6] T. L. Saaty, Decisions with the analytic network process (ANP). University of Pittsburgh, USA: ISAHP, 1996. 
[7] S-L. Si, X-Y. You, H-C. Liu, and P. Zhang, "DEMATEL technique: a systematic review of the state-of-the-art literature on methodologies and applications." Mathematical Problems in Engineering, vol. 2018, 2018, pp. 1-33. https://doi.org/10.1155/2018/3696457

[8] M. Reisi, A. Afsaneh, and A. Lu,"Applications of analytical hierarchy process (AHP) and analytical network process (ANP) for industrial site selections in Isfahan, Iran." Environmental Earth Sciences, vol.77, no. 537, 2018, pp.1-13. https://doi.org/10.1007/s12665-018-7702-1

[9] E. Ilbahar, A. Karaşan, S. Cebi, and C. Kahraman, "A novel approach to risk assessment for occupational health and safety using Pythagorean fuzzy AHP \& fuzzy inference system", Safety Science, vol. 103, 2018, pp. 124-136. https://doi.org/10.1016/j.ssci.2017.10.025

[10] J. Korpela, and M. Tuominen, "A decision aid in warehouse site selection." International Journal of Production Economics, vol. 45. no.1-3, 1996, pp. 169-180. https://doi.org/10.1016/09255273(95)00135-2

[11] C. Boonmee, Chawis, and C. Kasemset. "The Multi-Objective Fuzzy Mathematical Programming Model for Humanitarian Relief Logistics." Industrial Engineering \& Management Systems, vol. 19, no.1, pp.197-210, 2020. https://doi.org/10.7232/iems.2020.19.1.197

[12] F. Kutlu Gündoğdu, and C. Kahraman, Spherical Fuzzy Sets and Decision Making Applications. In: International Conference on Intelligent and Fuzzy Systems. Springer, Cham, 2019, pp. 979-987. https://doi.org/10.1007/978-3-030-23756-1 116

[13] M. Khaengkhan, C. Hotrawisaya, B. Kiranantawat, and M. R. Shaharudin, "Comparative analysis of multiple criteria decision making (MCDM) approach in warehouse location selection of agricultural products in Thailand", International Journal of Supply Chain Management, vol. 8, no. 5, pp. 168-175, 2019.

[14] I. Otay, and M. Jaller. "Multi-criteria and multi-expert wind power farm location selection using a pythagorean fuzzy analytic hierarchy process." International Conference on Intelligent and Fuzzy Systems. Springer, Cham, 2019. https://doi.org/10.1007/978-3-030-23756$1 \_108$

[15] F. Kutlu Gündoğdu, and C. Kahraman, "A novel VIKOR method using spherical fuzzy sets and its application to warehouse site selection", Journal of Intelligent \& Fuzzy Systems, vol. 37, no.1, 2019, pp. https://doi.org/1197-1211.10.3233/JIFS-182651

[16] S. Y. Roh, Y. R. Shin, and Y. J. Seo, "The Pre-positioned warehouse location selection for international humanitarian relief logistics", The Asian Journal of Shipping and Logistics, vol.34, no.4, pp.297-307, 2018.

[17] R. K. Singh, N. Chaudhary, and N. Saxena, " Selection of warehouse location for a global supply chain: A case study", IIMB Management Review, vol. 30, no.4, pp. 343-356, 2018.

[18] N. Foroozesh, R. Tavakkoli-Moghaddam, and S. M. Mousavi, "A novel group decision model based on mean-variance-skewness concepts and interval-valued fuzzy sets for a selection problem of the sustainable warehouse location under uncertainty", Neural Computing and Applications, vol.30, no.11, 2018, pp.3277-3293. https://doi.org/10.1007/s00521-017-2885-z

[19] Ş. Emeç, and G. Akkaya, "Stochastic AHP and fuzzy VIKOR approach for warehouse location selection problem", Journal of Enterprise Information Management, vol. 31 no. 6, 2018, pp. 950-962. https://doi.org/10.1108/JEIM-12-2016-0195

[20] B. Dey, B. Bairagi, B. Sarkar, and S. K. Sanyal, "Group heterogeneity in multi member decision making model with an application to warehouse location selection in a supply chain", Computers \& Industrial Engineering, vol.105, 2017, pp.101-122. https://doi.org/10.1016/j.cie.2016.12.025

[21] G. T. Temur, "A novel multi attribute decision making approach for location decision under high uncertainty", Applied Soft Computing, vol. 40, 2016, pp.674-682. https://doi.org/10.1016/j.asoc.2015.12.027

[22] B. Dey, B. Bairagi, B. Sarkar, and S. K. Sanyal, "Warehouse location selection by fuzzy multi-criteria decision making methodologies based on subjective and objective criteria", International Journal of Management Science and Engineering Management, vol.11, no.4, 2016, pp. 262-278. https://doi.org/10.1080/17509653.2015.1086964

[23] B. Malmir, A. Aghighi, M. N. Bisheh, A. Ala, B. A., Avilaq, and S. Dehghani, "Application of a new multi criteria decision making method for warehouse location problem", International Journal of Value Chain Management, vol.7, no.3, 2015, pp. 255-270. https://doi.org/10.1504/IJVCM.2016.079211

[24] C. Karmaker, and M. Saha, "Optimization of warehouse location through fuzzy multi-criteria decision making methods", Decision Science Letters, vol.4, no.3, 2015, pp.315-334. https://doi.org/10.5267/j.ds1.2015.4.005

[25] B. Malmir, R. Moein, and S.K. Chaharsooghi, "Selecting warehouse location by means of the balancing and ranking method with an interval approach." 2015 International Conference on Industrial Engineering and Operations Management (IEOM), IEEE, 2015, pp. 17. https://doi.org/10.1109/IEOM.2015.7093911

[26] F. Uysal, and Ö. Tosun, "Selection of sustainable warehouse location in supply chain using the grey approach", International Journal of Information and Decision Sciences, vol.6, no.4, 2014, pp.338-353. https://doi.org/10.1504/IJIDS.2014.066633

[27] I. U. Sarı, B. Öztayşi, and C. Kahraman, Fuzzy analytic hierarchy process using type-2 fuzzy sets: An application to warehouse location selection. In Multicriteria decision aid and artificial intelligence, John Wiley \& Sons, Ltd., 2013, pp. 285-308. https://doi.org/10.1002/9781118522516.ch12

[28] B. Dey, B. Bairagi, B. Sarkar, and S. K. Sanyal, "A hybrid fuzzy technique for the selection of warehouse location in a supply chain under a utopian environment", International Journal of Management Science and Engineering Management, vol.8, no.4, pp. 250-261, 2013.

[29] B. Dey, B. Bairagi, B. Sarkar, and S. K. Sanyal, "A MOORA based fuzzy multi-criteria decision making approach for supply chain strategy selection", International Journal of Industrial Engineering Computations, vol.3, no.4, 2012, pp. 649-662. https://doi.org/10.1080/17509653.2013.825075

[30] T. Özcan, N. Celebi, and S. Esnaf, "Comparative analysis of multicriteria decision making methodologies and implementation of a warehouse location selection problem", Expert Systems with Applications, vol.38, no.8, 2011, pp.9773-9779. https://doi.org/10.1016/j.eswa.2011.02.022

[31] T. Demirel, C. Demirel, and C. Kahraman, "Multi-criteria warehouse location selection using Choquet integral", Expert Systems with Applications, vol. 37, no.5, 2010, pp. 3943-3952. https://doi.org/10.1016/j.eswa.2009.11.022

[32] Q. Cao, X. Di, and X. Zhang, A simulated annealing methodology to estate logistic warehouse location selection and distribution of customers' requirement. In 2009 International Workshop on Intelligent Systems and Applications, IEEE, May 2009, pp. 1-4. https://doi.org/10.1109/IWISA.2009.5072676

[33] Ö. Senvar, U. R. Tuzkaya, and C. Kahraman, Supply chain performance measurement: an integrated DEMATEL and Fuzzy-ANP approach. In Supply Chain Management Under Fuzziness, Springer, Berlin, Heidelberg, 2014, pp. 143-165. https://doi.org/10.1007/978-3642-53939-8 7

[34] R.R. Yager, Properties and applications of Pythagorean fuzzy sets. In: Imprecision and Uncertainty in Information Representation and Processing. Springer, 2016, pp.119-136. https://doi.org/10.1007/9783-319-26302-1_9

[35] L., Abdullah and P. Goh, "Decision making method based on Pythagorean fuzzy sets and its application to solid waste management", Complex \& Intelligent Systems, vol. 5, no.2, 2019, pp. 185-198. https://doi.org/10.1007/s40747-019-0100-9

[36] R.R Yager, and A.M. Abbasov, "Pythagorean membership grades, complex numbers, and decision making", International Journal. Intelligent Systems, vol. 28 no.5, 2013, pp. 436-452. https://doi.org/10.1002/int.21584

[37] T. L. Saaty, "Fundamentals of the analytic network processDependence and feedback in decision-making with a single network", Journal of Systems Science and Systems Engineering, vol.13, 2004, pp.129-157. https://doi.org/10.1007/s11518-006-0158-y

[38] G. Büyüközkan, and G. Gizem, "A novel fuzzy multi-criteria decision framework for sustainable supplier selection with incomplete information." Computers in Industry, vol. 62 no.2, 2011, pp. 164-174. https://doi.org/10.1016/j.compind.2010.10.009

[39] T. Tuncalı Yaman, and G. R. Akkartal, "Warehouse location selection decision systems for medical sector (In press)", In: 2020 Fourth World Conference on Smart Trends in Systems Security and Sustainability (WorldS4), London, United Kingdom, 2020.

[40] A. Łodziński, "Multicriteria support of choosing a group decision," 2015 Federated Conference on Computer Science and Information Systems (FedCSIS), Lodz, 2015, pp. 1597-1602, https://doi.org/10.15439/2015F58. 